\title{
Population Structure of Botryosphaeria dothidea from Pistachio and Other Hosts in California
}

\author{
Zhonghua Ma, Eric W. A. Boehm, Yong Luo, and Themis J. Michailides
}

Department of Plant Pathology, University of California Davis, Kearney Agricultural Center, 9240 South Riverbend Ave., Parlier 93648. Accepted for publication 28 March 2001.

\section{ABSTRACT}

Ma, Z., Boehm, E. W. A., Luo, Y., and Michailides, T. J. 2001. Population structure of Botryosphaeria dothidea from pistachio and other hosts in California. Phytopathology 91:665-672.

Genetic diversity was investigated among California populations of Botryosphaeria dothidea, causal agent of Botryosphaeria panicle and shoot blight of pistachio, with random amplified polymorphic DNA (RAPD) and microsatellite-primed polymerase chain reaction (MP-PCR). We surveyed 120 isolates, 112 of which originated from the California Central Valley and included pistachio isolates $(n=52)$ and isolates from other plant species $(n=60)$. Out-group isolates $(n=8)$ were obtained from pistachio in Greece. There was a strong correlation $(r=0.99 ; P<$ 0.0001 ) between the RAPD- and MP-PCR dissimilarity data sets. Little genetic variation (haplotypic diversity $[H s]<0.002$ ) was detected among $B$. dothidea isolates collected from central and southern California pistachio plantings. We observed relatively high diversity for isolates from a northern California pistachio orchard $(H s=0.0146)$, where the disease was first diagnosed, and from the Chico U.S. Department of Agriculture
Germ Plasm Repository ( $H s=0.0726)$, where the first pistachio trees were planted in California in 1929. Isolates obtained from other hosts, especially those associated with the rare occurrence of the sexual stage of this fungus, showed the highest levels of diversity $(H s=0.1689)$. Thirty-eight pistachio isolates $(73.1 \%$ ) had DNA fingerprints identical to 28 pycnidiospore-derived isolates $(56.0 \%)$ obtained from other host species. Greenhouse inoculations demonstrated that all isolates obtained from other hosts were capable of infecting pistachio and produced characteristic disease symptomology. Thus, California populations of $B$. dothidea from pistachio are, for the most part, genetically uniform, with the sexual stage rare to absent. However, the rare occurrence of the sexual stage of $B$. dothidea on other hosts, and more importantly, the capacity of these isolates to infect pistachio, indicate that other host species may serve as sources of inoculum and genetic variation.

Additional keywords: epidemiology, molecular markers, nut crop diseases, Pistacia vera.

B. dothidea has been recovered from more than 35 different plant species in California (12). Although the sexual stage of $B$. dothidea is infrequent in nature, ascocarps (i.e., pseudothecia) have been reported from giant sequoia (Sequoiadendron giganteum) and coastal redwood (Sequoia sempervirens) in California (32), and from blueberry (30), elm (5), peach (28), apple (25), and willow (31) in the eastern United States. However, the sexual stage has not been found in diseased pistachio (12). Thus, at present it is assumed that population of $B$. dothidea on California pistachio is primarily asexual.

The large number of native and introduced plant species from which $B$. dothidea has been recovered has led to the suggestion that these hosts may potentially serve as inoculum sources, and may pose a threat to commercial pistachio plantings in California (12). Early reports of B. dothidea on English walnut and willow (3) and on lemon, avocado, walnut, and palm (21), suggest that the pathogen was present in California before pistachios were introduced as a commercial crop in the early 1970s (27). In preliminary tests, nearly all $B$. dothidea isolates recovered from other hosts were capable of infecting detached pistachio fruits, producing typical pycnidia. Similar results were obtained from repeated field inoculation studies (12). These findings suggest that populations of $B$. dothidea from other hosts have moved into and infected susceptible pistachio. Hemipteran insect vectors have been shown to vector the pathogen from other hosts into pistachio and between pistachio plantings (15). Birds have also been implicated as vectors (T. J. Michailides, unpublished data).

The study of the genetic structure of California populations of $B$. dothidea might help resolve such issues as whether isolates collected from pistachio are genetically related to those collected from other hosts. This information may have some bearing on predicting pathogen movement and control strategies for the 
disease. Preliminary studies of genetic diversity among California pistachio isolates of $B$. dothidea have indicated a low level of genetic diversity $(2,23)$. However, these studies surveyed only a small number of $B$. dothidea pistachio isolates, and no isolates from other hosts were included. We initiated this study to examine a large population of California $B$. dothidea isolates $(n=112)$, originating from pistachio and a number of other hosts (walnut, willow, pecan, blackberry, and eucalyptus) that grow adjacent to commercial pistachio plantings.

The polymerase chain reaction (PCR) forms the basis for many molecular methodologies for assessing population diversity among fungal plant pathogens $(6,26)$. Recently, oligonucleotide fingerprinting probes specific to microsatellite or simple sequence repeats (8) have been used in microsatellite-primed (MP) PCR (29). MP-PCR is considered more robust than conventional random amplified polymorphic DNA (RAPDs) (6) analyses, because longer primers are used for MP-PCR than for RAPDs. This allows more stringent annealing temperatures $\left(>45^{\circ} \mathrm{C}\right)$ and reaction conditions that enhance reproducibility and avoid spurious amplification based on partial primer binding $(24,29)$.

In this study, we used both RAPDs and MP-PCR to assess genetic diversity among populations of $B$. dothidea from pistachio and from other hosts throughout California, and out-group isolates from two pistachio orchards in Greece. Our objective was to assess genetic diversity among growing regions, and among different hosts in California. Our second objective was to assess whether isolates of $B$. dothidea obtained from other hosts can infect pistachio and produce the characteristic disease symptomology. This information is considered prerequisite to formulate a better understanding of disease outbreaks, predict future disease development, and develop effective disease management strategies.

\section{MATERIALS AND METHODS}

Fungal isolates. We surveyed 120 single-spore isolates of $B$. dothidea for genetic diversity (Table 1). Blighted panicles and shoots of pistachio and other hosts were collected from throughout California, yielding isolates from Kings County $(n=7)$ in the south, Madera County $(n=6)$ and San Joaquin County $(n=4)$ in the center of the state, and from Butte County $(n=20)$ and Glenn County $(n=75)$ in the north. Ten of the isolates from Butte County were obtained from the Montgomery Pistachio Orchard, the first orchard in which Botryosphaeria panicle and shoot blight disease was recorded in 1984 (20). The other 10 isolates from Butte County were obtained from pistachio trees that originated from the first pistachio seed brought from Iran by W. E. Whitehouse in 1929 at the Chico U.S. Department of Agriculture Germ Plasm Repository (USDA GR) (27). These two latter sites were chosen because they represent the oldest pistachio collections in the state and, presumably, serve as a center of origin for the disease. The set of 75 isolates from Glenn County were obtained from pistachio and from other hosts at a single site. This site was chosen because of the abundance of other hosts for $B$. dothidea adjacent to a commercial pistachio orchard. Twenty of the seventy-five isolates (10 ascospore isolates and 10 pycnidiospore isolates) were collected from California blackberry (Rubus ursinus) from which the sexual stage of the fungus had previously been recovered (13). We also collected 10 pycnidiospore isolates each from eucalyptus, pecan, walnut, and willow and 15 isolates from pistachio (Table 1). Thus, 112 isolates were established for $B$. dothidea from a diverse array of geographic locations in California, representing different collection dates and hosts. Out-group isolates $(n=8)$ were obtained from pistachio in Aegina and Thessaloniki in central and northern Greece, respectively (Table 1).

To obtain single spore isolates, infected plants were examined for $B$. dothidea infections and for characteristic pycnidia or pseudothecia of the pathogen. Single pycnidia were cut open under a dissecting microscope and placed in $500 \mu \mathrm{l}$ of sterile water to produce a spore suspension. A $20-\mu \mathrm{l}$ aliquot was spread on an acidified $(2.5 \mathrm{ml}$ of a $25 \%$ [vol/vol] solution of lactic acid per liter of medium) potato dextrose agar (APDA) (Microtech Scientific, Orange, CA) plate and incubated at $29^{\circ} \mathrm{C}$ for 2 days. Single pycnidiospore isolates of $B$. dothidea from each plate were recovered and transferred to new plates. To isolate single ascospore isolates, small pieces of blackberry shoots carrying pseudothecia were stuck on APDA plate lids. The plates were incubated at room temperature $\left(25 \pm 2^{\circ} \mathrm{C}\right)$ overnight. The next day, single germinating ascospore were taken under a microscope and transferred to new plates. Verification of the isolates of $B$. dothidea recovered from other hosts was based upon colony morphology growing on APDA and characteristic pycnidia and pycnidiospores producing on inoculated autoclaved pistachio leaves (pathogenicity tests).

DNA extraction. All $B$. dothidea isolates were grown in potato dextrose broth (Difco Laboratories, Detroit) cultures at $29^{\circ} \mathrm{C}$ for 4 days. Mycelia were harvested and washed in sterile water, snap frozen in liquid nitrogen, and lyophilized. Total genomic DNA was extracted by a modification of a previously published protocol (7). Briefly, dried fungal material (100 mg) was ground with a motor-driven pestle and sterile white quartz sand in $5 \mathrm{ml}$ of hot $\left(68^{\circ} \mathrm{C}\right)$ extraction buffer $(1 \%$ hexadecyltreimethylammonium bromide [CTAB], $700 \mathrm{mM} \mathrm{NaCl}, 50 \mathrm{mM}$ Tris-HCl, pH 8.0, $10 \mathrm{mM}$ EDTA, and $1 \% \beta$-mercaptoethanol) in a $16-\mathrm{ml}$ centrifuge tube. An equal volume of chloroform/isoamyl alcohol (24:1) was added to emulsify. The tubes were spun for $10 \mathrm{~min}$ at 7,000 rpm. The supernatants were transferred to new tubes, and an equal volume of isopropanol was added to precipitate the nucleic acids. Subsequently, the tubes were spun for $15 \mathrm{~min}$ at $10,000 \mathrm{rpm}$. Recovered nucleic acid pellets were suspended in TE $(50 \mathrm{mM}$ Tris- $\mathrm{HCl}$, $\mathrm{pH} 8.0$, and $10 \mathrm{mM}$ EDTA) with RNase $(20 \mu \mathrm{g} / \mathrm{ml})$, transferred to $1.5-\mathrm{ml}$ tubes, and incubated at $37^{\circ} \mathrm{C}$ for $30 \mathrm{~min}$. To further purify the DNA, a phenol/chloroform/isoamyl alcohol (25:24:1) extraction was done, followed by two chloroform extractions. Final DNA pellets were washed with $70 \%$ ethanol and suspended in TE. DNA concentrations were standardized to $5 \mathrm{ng} / \mu \mathrm{l}$ by a fluorometer (Hoefer DyNA Quant 200; Hoefer Pharmacia Biotech Inc., San Francisco).

PCR amplifications. For MP-PCR, a total of six microsatellite primers, $(\mathrm{CAC})_{5},(\mathrm{GTG})_{5},(\mathrm{GACA})_{4},(\mathrm{GATA})_{4}$, the $\mathrm{M} 13$ repetitive core sequence GAG GGT GGC GGT TCT (8), and the telomeric repeat $(\mathrm{CCCTAA})_{4}(4)$, were screened for their utility in producing PCR products. For RAPDs, 13 commercial primers (Operon Technologies, Alameda, CA) were screened for their utility in producing PCR bands. To optimize conditions, a range of template (10 to $100 \mathrm{ng}$ ) and $\mathrm{MgCl}_{2}$ concentrations (1 to $5 \mathrm{mM}$ ) were assayed, as well as a series of different annealing temperatures. PCR reactions were performed by a thermal cycler (Model 480; Perkin-Elmer Corp., Norwalk, CT) in a 50- $\mu$ l volume containing $50 \mathrm{ng}$ of fungal genomic template, $1.0 \mu \mathrm{M}$ each microsatellite primer or $0.2 \mu \mathrm{M}$ each Operon primer, $0.2 \mathrm{mM}$ each of dNTP, $2.0 \mathrm{mM} \mathrm{MgCl}$ for microsatellite primers, $2.5 \mathrm{mM}$ for primer K19 and K20, or $3.0 \mathrm{mM}$ for primer R13 and R15, 1× Promega Taq polymerase buffer (10 mM Tris- $\mathrm{HCl}, \mathrm{pH} 9.0,50 \mathrm{mM} \mathrm{KCl}$, and $0.1 \%$ Triton $\mathrm{X}-100)$, and 1.5 units of Taq polymerase (Promega Corp., Madison, WI). The following final run parameters were used: an initial preheat for $2 \mathrm{~min}$ at $95^{\circ} \mathrm{C}$, followed by 40 cycles of denaturation at $94^{\circ} \mathrm{C}$ for $1 \mathrm{~min}$, annealing at $50^{\circ} \mathrm{C}$ for $1 \mathrm{~min}$ for the microsatellite primers or $35^{\circ} \mathrm{C}$ for the Operon primers, and extension at $72^{\circ} \mathrm{C}$ for $1.5 \mathrm{~min}$, and terminated with a final extension at $72^{\circ} \mathrm{C}$ for $10 \mathrm{~min}$. Each isolate was amplified twice. The PCR products were sepaated on $1.5 \%$ agarose gels and photographed after staining with ethidium bromide.

Data analysis. Each isolate was scored for the presence or absence of each amplicon. Genetic similarities $(S)$ were calculated with the coefficient of similarity given by Nei and Li (19) as $S=$ $2 N_{a b} /\left(N_{a}+N_{b}\right)$, where $N_{a b}$ is the number of amplicons shared by two isolates, and $N_{a}$ and $N_{b}$ are the number of amplicons found in 
isolate $a$ and $b$, respectively. Genetic distances $(G)$ (i.e., dissimilarities) were computed as $G=1-S$. Two separate data sets were constructed for the RAPD and MP-PCR. The correlation between RAPD and MP-PCR genetic dissimilarity data was tested using the procedure CORR of SAS (version 8.0, SAS Institute, Cary, NC).
The combined binary data sets for both RAPDs and MP-PCR were assembled and used to construct a phenogram by a computer program phylogenetic analysis using parsimony (PAUP version 4.0b4a; Sinauer Associates Inc., Sunderland, MA) using the unweighted pair-group method with arithmetic average (UPGMA).

TABLE 1. Botryosphaeria dothidea isolates collected from pistachio and other hosts used in this study and pathogenicity tests on pistachio

\begin{tabular}{|c|c|c|c|c|c|c|c|c|c|c|c|}
\hline Isolate $^{\mathrm{a}}$ & Host & Location $^{\mathrm{b}}$ & $\begin{array}{c}\text { Isolation } \\
\text { date }\end{array}$ & $\begin{array}{l}\text { Pistachio } \\
\text { infection }^{c}\end{array}$ & $\begin{array}{l}\text { Pycnidia } \\
\text { production }^{\mathrm{d}}\end{array}$ & Isolate $^{\mathrm{a}}$ & Host & Location $^{\mathrm{b}}$ & $\begin{array}{c}\text { Isolation } \\
\text { date }\end{array}$ & $\begin{array}{l}\text { Pistachio } \\
\text { infection }^{\mathrm{c}}\end{array}$ & $\begin{array}{c}\text { Pycnidia } \\
\text { production }^{\mathrm{d}}\end{array}$ \\
\hline KP 94 & Pistachio & Kings & $10 / 23 / 97$ & + & + & HBL 1 & Blackberry & Hansen & 7/1/99 & + & + \\
\hline KP 95 & Pistachio & Kings & $10 / 23 / 97$ & $\ldots$ & $\ldots$ & HBL 5 & Blackberry & Hansen & $4 / 4 / 00$ & + & + \\
\hline KP 96 & Pistachio & Kings & $10 / 23 / 97$ & $\ldots$ & $\ldots$ & HBL 6 & Blackberry & Hansen & $4 / 4 / 00$ & + & + \\
\hline KP 97 & Pistachio & Kings & $10 / 23 / 97$ & $\ldots$ & $\ldots$ & HBL 7 & Blackberry & Hansen & $4 / 4 / 00$ & + & + \\
\hline KP 98 & Pistachio & Kings & $10 / 23 / 97$ & $\ldots$ & $\ldots$ & HBL 9 & Blackberry & Hansen & $4 / 4 / 00$ & + & + \\
\hline KP 99 & Pistachio & Kings & $10 / 23 / 97$ & $\ldots$ & $\ldots$ & HBL 10 & Blackberry & Hansen & $4 / 4 / 00$ & + & + \\
\hline KP 100 & Pistachio & Kings & $10 / 23 / 97$ & $\ldots$ & $\ldots$ & HBL 11 & Blackberry & Hansen & $4 / 4 / 00$ & + & + \\
\hline MAP 103 & Pistachio & Madera & $10 / 23 / 97$ & + & + & HBL 12 & Blackberry & Hansen & $4 / 4 / 00$ & + & + \\
\hline MAP 106 & Pistachio & Madera & $10 / 23 / 97$ & $\ldots$ & $\ldots$ & HBL 14 & Blackberry & Hansen & $4 / 4 / 00$ & + & + \\
\hline MAP 108 & Pistachio & Madera & $10 / 23 / 97$ & $\ldots$ & $\ldots$ & HBL 15 & Blackberry & Hansen & $4 / 4 / 00$ & + & + \\
\hline MAP 111 & Pistachio & Madera & $10 / 23 / 97$ & $\ldots$ & $\ldots$ & HEU 1 & Eucalyptus & Hansen & $4 / 4 / 00$ & + & + \\
\hline MAP 188 & Pistachio & Madera & $1 / 25 / 99$ & $\ldots$ & $\ldots$ & HEU 2 & Eucalyptus & Hansen & $4 / 4 / 00$ & + & + \\
\hline MAP 197 & Pistachio & Madera & $1 / 28 / 99$ & $\ldots$ & $\ldots$ & HEU 3 & Eucalyptus & Hansen & $4 / 4 / 00$ & + & + \\
\hline SP 81 & Pistachio & San Joaquin & 9/7/97 & + & + & HEU 4 & Eucalyptus & Hansen & $4 / 4 / 00$ & + & + \\
\hline SP 132 & Pistachio & San Joaquin & $10 / 27 / 97$ & $\ldots$ & $\ldots$ & HEU 5 & Eucalyptus & Hansen & $4 / 4 / 00$ & + & + \\
\hline SP 133 & Pistachio & San Joaquin & $10 / 27 / 97$ & $\ldots$ & $\ldots$ & HEU 6 & Eucalyptus & Hansen & $4 / 4 / 00$ & + & + \\
\hline SP 200 & Pistachio & San Joaquin & $1 / 28 / 99$ & $\ldots$ & $\ldots$ & HEU 7 & Eucalyptus & Hansen & $4 / 4 / 00$ & + & + \\
\hline MP 1 & Pistachio & Montgomery & $4 / 4 / 00$ & $\ldots$ & $\ldots$ & HEU 8 & Eucalyptus & Hansen & $4 / 4 / 00$ & + & + \\
\hline MP 2 & Pistachio & Montgomery & $4 / 4 / 00$ & $\ldots$ & $\ldots$ & HEU 9 & Eucalyptus & Hansen & $4 / 4 / 00$ & + & + \\
\hline MP 3 & Pistachio & Montgomery & $4 / 4 / 00$ & $\ldots$ & $\ldots$ & HEU 10 & Eucalyptus & Hansen & $4 / 4 / 00$ & + & + \\
\hline MP 4 & Pistachio & Montgomery & $4 / 4 / 00$ & $\ldots$ & $\ldots$ & HPE 1 & Pecan & Hansen & $4 / 4 / 00$ & + & + \\
\hline MP 5 & Pistachio & Montgomery & $4 / 4 / 00$ & $\ldots$ & $\ldots$ & HPE 2 & Pecan & Hansen & $4 / 4 / 00$ & + & + \\
\hline MP 6 & Pistachio & Montgomery & $4 / 4 / 00$ & $\ldots$ & $\ldots$ & HPE 3 & Pecan & Hansen & $4 / 4 / 00$ & + & + \\
\hline MP 7 & Pistachio & Montgomery & $4 / 4 / 00$ & $\ldots$ & $\ldots$ & HPE 4 & Pecan & Hansen & $4 / 4 / 00$ & + & + \\
\hline MP 8 & Pistachio & Montgomery & $4 / 4 / 00$ & $\ldots$ & $\ldots$ & HPE 5 & Pecan & Hansen & $4 / 4 / 00$ & + & + \\
\hline MP 9 & Pistachio & Montgomery & $4 / 4 / 00$ & $\ldots$ & $\ldots$ & HPE 6 & Pecan & Hansen & $4 / 4 / 00$ & + & + \\
\hline MP 10 & Pistachio & Montgomery & $4 / 4 / 00$ & $\ldots$ & $\ldots$ & HPE 7 & Pecan & Hansen & $4 / 4 / 00$ & + & + \\
\hline $\mathrm{CP} 1$ & Pistachio & Chico & $4 / 4 / 00$ & $\ldots$ & $\ldots$ & HPE 8 & Pecan & Hansen & $4 / 4 / 00$ & + & + \\
\hline $\mathrm{CP} 2$ & Pistachio & Chico & $4 / 4 / 00$ & $\ldots$ & $\ldots$ & HPE 9 & Pecan & Hansen & $4 / 4 / 00$ & + & + \\
\hline CP 3 & Pistachio & Chico & $4 / 4 / 00$ & $\ldots$ & $\ldots$ & HPE 10 & Pecan & Hansen & $4 / 4 / 00$ & + & + \\
\hline $\mathrm{CP} 4$ & Pistachio & Chico & $4 / 4 / 00$ & + & + & HWA 1 & Walnut & Hansen & $7 / 1 / 99$ & + & + \\
\hline CP 5 & Pistachio & Chico & $4 / 4 / 00$ & $\ldots$ & $\ldots$ & HWA 2 & Walnut & Hansen & $7 / 1 / 99$ & + & + \\
\hline CP 6 & Pistachio & Chico & $4 / 4 / 00$ & $\ldots$ & $\ldots$ & HWA 3 & Walnut & Hansen & $7 / 1 / 99$ & + & + \\
\hline CP 7 & Pistachio & Chico & $4 / 4 / 00$ & $\ldots$ & $\ldots$ & HWA 7 & Walnut & Hansen & 7/1/99 & + & + \\
\hline CP 8 & Pistachio & Chico & $4 / 4 / 00$ & $\ldots$ & $\ldots$ & HWA 8 & Walnut & Hansen & $7 / 1 / 99$ & + & + \\
\hline CP 9 & Pistachio & Chico & $4 / 4 / 00$ & $\ldots$ & $\ldots$ & HWA 10 & Walnut & Hansen & $7 / 1 / 99$ & + & + \\
\hline CP 10 & Pistachio & Chico & $4 / 4 / 00$ & $\ldots$ & $\ldots$ & HWA 12 & Walnut & Hansen & $4 / 4 / 00$ & + & + \\
\hline AGP 116 & Pistachio & Aegina & $10 / 23 / 97$ & + & + & HWA 13 & Walnut & Hansen & $4 / 4 / 00$ & + & + \\
\hline AGP 120 & Pistachio & Aegina & $10 / 23 / 97$ & + & + & HWA 14 & Walnut & Hansen & $4 / 4 / 00$ & + & + \\
\hline AGP 123 & Pistachio & Aegina & $10 / 23 / 97$ & $\ldots$ & $\ldots$ & HWA 15 & Walnut & Hansen & $4 / 4 / 00$ & + & + \\
\hline AGP 124 & Pistachio & Aegina & $10 / 23 / 97$ & $\ldots$ & $\ldots$ & HWI 1 & Willow & Hansen & $7 / 1 / 99$ & + & + \\
\hline TGP 128 & Pistachio & Thessaloniki & $10 / 23 / 97$ & + & + & HWI 2 & Willow & Hansen & $7 / 1 / 99$ & + & + \\
\hline TGP 129 & Pistachio & Thessaloniki & $10 / 23 / 97$ & $\ldots$ & $\ldots$ & HWI 3 & Willow & Hansen & $7 / 1 / 99$ & + & + \\
\hline TGP 130 & Pistachio & Thessaloniki & $10 / 23 / 97$ & + & + & HWI 4 & Willow & Hansen & $7 / 1 / 99$ & + & + \\
\hline TGP 131 & Pistachio & Thessaloniki & $10 / 23 / 97$ & $\ldots$ & $\ldots$ & HWI 5 & Willow & Hansen & $7 / 1 / 99$ & + & + \\
\hline HP 2 & Pistachio & Hansen & $7 / 1 / 99$ & $\ldots$ & $\ldots$ & HWI 11 & Willow & Hansen & $7 / 1 / 99$ & + & + \\
\hline HP 3 & Pistachio & Hansen & $7 / 1 / 99$ & $\ldots$ & $\ldots$ & HWI 12 & Willow & Hansen & $4 / 4 / 00$ & + & + \\
\hline HP 4 & Pistachio & Hansen & $7 / 1 / 99$ & $\ldots$ & $\ldots$ & HWI 13 & Willow & Hansen & $4 / 4 / 00$ & + & + \\
\hline HP 5 & Pistachio & Hansen & $9 / 1 / 94$ & $\ldots$ & $\ldots$ & HWI 14 & Willow & Hansen & $4 / 4 / 00$ & + & + \\
\hline HP 6 & Pistachio & Hansen & $9 / 1 / 94$ & $\ldots$ & $\ldots$ & HWI 15 & Willow & Hansen & $4 / 4 / 00$ & + & + \\
\hline HP 7 & Pistachio & Hansen & $9 / 1 / 94$ & $\ldots$ & $\ldots$ & AS 1 & Blackberry & Hansen & $4 / 4 / 00$ & + & + \\
\hline HP 8 & Pistachio & Hansen & $9 / 1 / 94$ & $\ldots$ & $\ldots$ & AS 2 & Blackberry & Hansen & $4 / 4 / 00$ & + & + \\
\hline HP 9 & Pistachio & Hansen & $9 / 1 / 94$ & $\begin{array}{l}\cdots \\
\ldots\end{array}$ & $\begin{array}{l}\cdots \\
\cdots\end{array}$ & AS 4 & Blackberry & Hansen & $4 / 4 / 00$ & + & + \\
\hline HP 10 & Pistachio & Hansen & $9 / 1 / 94$ & $\ldots$ & $\ldots$ & AS 5 & Blackberry & Hansen & $4 / 4 / 00$ & + & + \\
\hline HP 11 & Pistachio & Hansen & $9 / 1 / 94$ & $\ldots$ & $\ldots$ & AS 6 & Blackberry & Hansen & $4 / 4 / 00$ & + & + \\
\hline HP 13 & Pistachio & Hansen & $4 / 4 / 00$ & $\ldots$ & $\ldots$ & AS 13 & Blackberry & Hansen & $4 / 4 / 00$ & + & + \\
\hline HP 14 & Pistachio & Hansen & $4 / 4 / 00$ & $\ldots$ & $\ldots$ & AS 15 & Blackberry & Hansen & $4 / 4 / 00$ & + & + \\
\hline HP 16 & Pistachio & Hansen & $4 / 4 / 00$ & $\ldots$ & $\ldots$ & AS 16 & Blackberry & Hansen & $4 / 4 / 00$ & + & + \\
\hline HP 17 & Pistachio & Hansen & $4 / 4 / 00$ & $\ldots$ & $\ldots$ & AS 18 & Blackberry & Hansen & $4 / 4 / 00$ & + & + \\
\hline HP 18 & Pistachio & Hansen & $4 / 4 / 00$ & $\ldots$ & $\ldots$ & AS 20 & Blackberry & Hansen & $4 / 4 / 00$ & + & + \\
\hline
\end{tabular}

${ }^{a}$ All B. dothidea isolates were derived from single pycnidiospores, except for isolates designated AS, from blackberry, Hansen Pistachio Orchard, Orland, Glenn County, which were derived from single ascospores.

${ }^{\mathrm{b}}$ Kings, Madera, and San Joaquin are counties located in California; and Aegina and Thessaloniki are located in Greece. Montgomery Pistachio Orchard, Butte County, the first commercial orchard in California. Chico indicates the U.S. Department of Agriculture Germ Plasm Repository, Chico, Butte County, CA, the first site where pistachio was introduced from Iran in 1929.

$c+$ Denotes that the isolate originated from other host and infected pistachio and caused characteristic disease symptomology.

$\mathrm{d}+$ Denotes that the isolate produced characteristic pycnidia on pistachio leaves after 2 weeks of incubation. 
A $50 \%$ majority-rule consensus tree was generated by 1,000 replications of the bootstrapped algorithm to determine branch strengths. The genetic diversity of $B$. dothidea populations from each location or each host was estimated with Nei's haplotypic diversity index $(H s)(18)$. The maximum genetic diversity is given as 1 , whereas a genetic diversity of 0 indicates a genetically uniform population composed of a single clonal lineage. A genetic differentiation coefficient (Gst) among six populations from different locations or seven populations from different hosts was calculated as $G s t=(H t-H s) / H t$, where $H s$ is the average of estimated haplotypic diversities of the populations and $H t$ is an estimate of the haplotypic diversity of the total population. The analyses of $H s$, Gst, and Nei's genetic identity and genetic distance between populations were performed using the computer software POPGENE (version 1.32, University of Alberta, Edmonton, Canada). The relationship between haplotypic diversities and geographic distances was tested by exponential regression analysis using the computer software SigmaPlot (version 5.0, SPSS Inc., Richmond, CA).

Pathogenicity tests. A total of 60 isolates obtained from other hosts were assayed for their ability to cause disease on susceptible pistachio cv. Kerman in the greenhouse. These included pycnidiospore isolates originating from eucalyptus $(n=10)$, pecan $(n=$ $10)$, walnut $(n=10)$, willow $(n=10)$, and blackberry $(n=10)$ and 10 ascospore isolates from blackberry (Table 1). Positive controls were isolates taken from pistachio collected from Kings County $(n=1)$, Madera County $(n=1)$, San Joaquin County $(n=1)$, Butte County $(n=1)$, Aegina, Greece $(n=2)$, and Thessaloniki, Greece $(n=2)$. Mycelial plugs for each isolate were transferred to autoclaved pistachio leaves that were placed on the surface of agar in plates supplemented with $5 \mathrm{ml}$ of half-strength APDA (20 g of potato dextrose agar and $10 \mathrm{~g}$ of agar per liter of medium) in the bottom. Pycnidia developed on the leaves after 2 weeks incubation at room temperature $\left(25 \pm 2^{\circ} \mathrm{C}\right)$. To prepare spore suspensions for pistachio inoculations, plates for each isolate were flooded with sterile water, filtered through two layers of sterile cheesecloth, and the spore concentration adjusted to 10,000 spores per $\mathrm{ml}$ with a hemacytometer. In the greenhouse, one healthy pistachio shoot was sprayed with $50 \mathrm{ml}$ of each spore suspension by a handsprayer and the negative control shoot was sprayed with $50 \mathrm{ml}$ of water. Each inoculated shoot was covered with a plastic bag for
$12 \mathrm{~h}$ to maintain high relative humidity. Infected pistachio leaves were examined for characteristic symptomology of Botryosphaeria blight 15 days after inoculation.

Twenty days after inoculation, two infected leaves for each isolate were collected, surface-sterilized for $10 \mathrm{~min}$ in $0.05 \%$ sodium hypochlorite, and rinsed three times with sterile water. Each surface-sterilized leaf was placed in a 9-cm-diameter petri dish with $5 \mathrm{ml}$ of half-strength APDA. After 2 weeks incubation at room temperature, plates were examined for the production of characteristic pycnidia and pycnidiospores of the anamorph of $B$. dothidea.

\section{RESULTS}

MP-PCR. Three of the six microsatellite primers, $(\mathrm{GTG})_{5}$, $(\mathrm{GACA})_{4}$, and the M13 core sequence, consistently generated strong amplification products from $B$. dothidea genomic DNA template, whereas the other three microsatellite primers were problematical and were not included. The same MP-PCR band profiles were consistently produced for each screened primer. We observed no changes in overall banding patterns, although there were occasionally changes in band intensity. Examples of MP-PCR haplotypes derived from $(\mathrm{GTG})_{5}$ and the M13 core sequence are presented in Figure $1 \mathrm{~A}$ and $\mathrm{B}$, respectively. The three microsatellite primers generated 23 polymorphic amplicons total for the 120 isolates. Cluster analysis of the MP-PCR data revealed that 96 of 102 California $B$. dothidea pycnidiospore isolates had similar haplotypes, and genetic distances among these isolates were small. The isolate $\mathrm{CP} 4$, which originated from one of the original pistachio trees in Chico, Butte County, had the same band pattern as did blackberry-derived ascospore isolates AS1, AS2, AS5, AS6, and AS15, which were collected from Hansen, Glenn County, located $45 \mathrm{~km}$ west of Chico. The blackberry pycnidiospore isolates from Hansen, HBL11 and HBL1, were identical to HWA3 from walnut, and HWI4 and HWI5 from willow, respectively. The out-group $B$. dothidea isolates obtained from Greece (such as TGP128 and AGP116) were strikingly different from the California isolates.

RAPD-PCR. Of the 13 RAPD primers screened, only four, K19 (CAC AGG CGG A), K20 (GTG TCG CGA G), R13 (GGA CGA CAA G), and R15 (GGA CAA CGA G), consistently produced reliable amplification products. The four RAPD primers

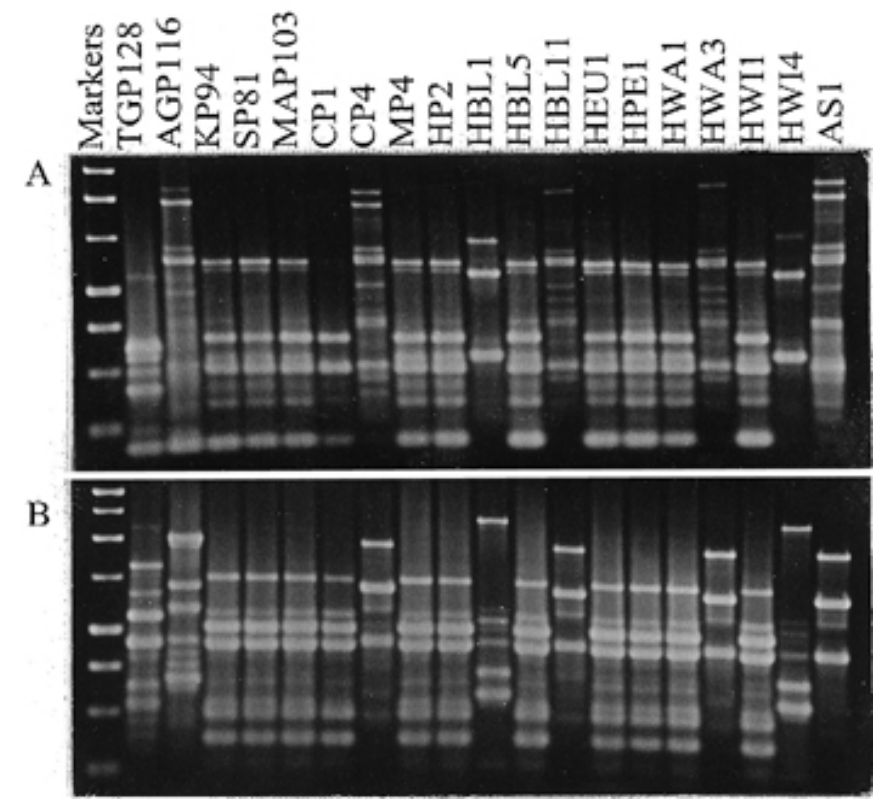

Fig. 1. Electrophoretic separation of DNA haplotypes of Botryosphaeria dothidea isolates obtained with $\mathbf{A}$, microsatellite primer $(\mathrm{GACA})_{4}$ and $\mathbf{B}$, primer derived from the core sequence of M13.

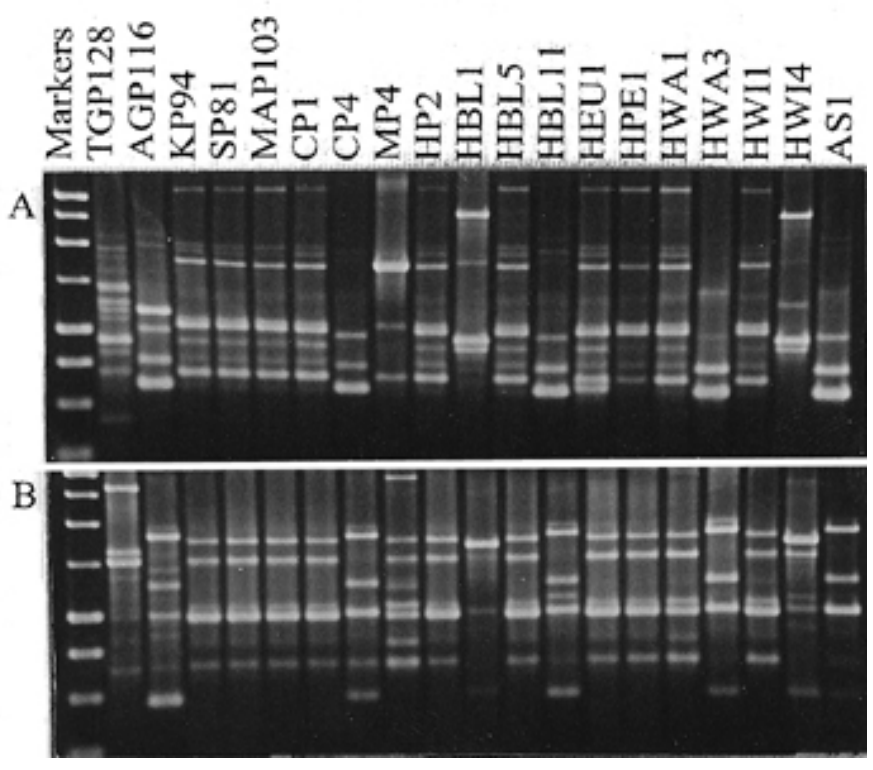

Fig. 2. Electrophoretic separation of DNA haplotypes of Botryosphaeria dothidea isolates obtained with Operon oligonucleotide primer A, R13 and B, R15. 
produced a total of 32 polymorphic amplicons for the 120 isolates. Examples of RAPD haplotypes are presented in Figure 2A and B. After PCR conditions were optimized, consistent high-intensity band profiles were obtained over several separate determinations, even when templates originating from different DNA extractions were used. In the comparative analysis, only high-intensity bands were scored for calculation of genetic diversity. Analysis of the RAPD data set indicated that 96 of 102 California pycnidiospore isolates were very similar. These 96 isolates were also clustered together according to MP-PCR data set. The pycnidiospore black-

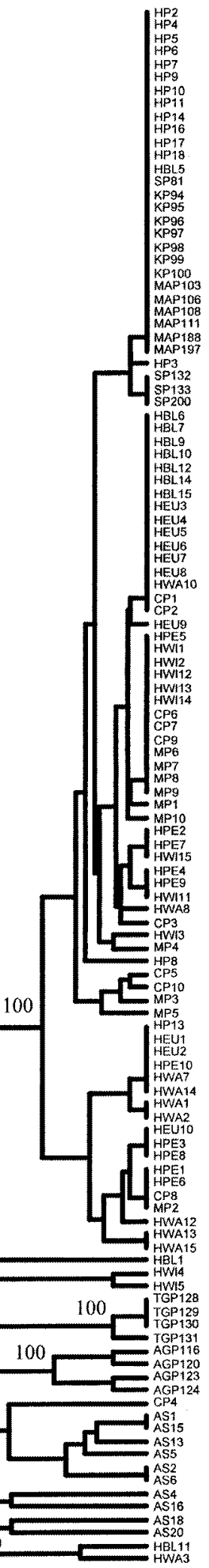

\section{-0.005 Genetic distance}

Fig. 3. Phenogram generated by the unweighted pair-group method with arithmetic average cluster analysis of random amplified polymorphic DNA and microsatellite-primed polymerase chain reaction data sets from 120 isolates of Botryosphaeria dothidea. Values on the branches of clusters represent results of bootstrap analysis (the percentage of times the group occurred during 1,000 replications). 
berry isolates HBL11 and HBL1 were again similar to walnut isolate HWA3, and to willow isolates HWI4 and HWI5, respectively. Isolate $\mathrm{CP} 4$, from $\mathrm{Chico}$, and the blackberry ascospore isolates from Hansen Orchard all had similar haplotypes. The eight Greek isolates were significantly different from the California isolates.

Combined data sets. Because there was a strong correlation ( $r=0.99 ; P<0.0001)$ between the RAPD- and MP-PCR dissimilarity data, the two data sets were combined. UPGMA analysis of the combined data sets subdivided the $B$. dothidea isolates into six groups (Fig. 3). Bootstrap analysis showed that all major branches were supported at the $100 \%$ level (Fig. 3). Group 1 contained 51 of the 52 isolates collected from California pistachio, as well as 45 of the 50 pycnidiospore isolates from other hosts. Groups 2 and 6 had three and two isolates, respectively, obtained from blackberry, willow, and walnut from the Hansen Orchard. Groups 3 and 4 contained all of the Greece out-group B. dothidea isolates, and group 5 contained all of the ascospore isolates collected from California blackberry from the Hansen Orchard, as well as a single pycnidiospore isolate from pistachio in Chico, Butte County (i.e., CP4).

In general, the RAPD- and MP-PCR data sets indicated that there were high genetic identities and low genetic distances between populations from different locations (Table 2) or from different hosts (Table 3). Nevertheless, we observed sufficient genetic diversity among the isolate collection to identify trends in variation that correlate with both the postulated geographic spread of the disease from north to south, and with the type of host from which isolates were recovered (Figs. 4 and 5). For pistachio isolates originating from six geographic regions, the highest level of genetic diversity $(H s=0.0726)$ was from 10 isolates obtained from the USDA GR in Chico, Butte County, where pistachios were first planted in California in 1929 (27). Isolates originating from the Montgomery Orchard, Butte County $(n=10)$, located $10 \mathrm{~km}$ from the USDA GR, the site from which Botryosphaeria panicle and shoot blight was first recorded (20), represented the second highest level of genetic diversity $(H s=0.0146)$, whereas isolates originating from Glenn County $(n=15), 40 \mathrm{~km}$ from USDA GR, had low levels of diversity $(H s=0.0059)$. These three collection sites were all from the northern Sacramento Valley, where the disease was first detected and from where the disease has postulated to have spread southward (15). The remaining pistachio isolates sampled from San Joaquin County $(n=4)$ and Madera County $(n=7), 180$ and $280 \mathrm{~km}$ from USDA GR, respectively, and from Kings County $(n=6), 375 \mathrm{~km}$ from USDA GR, had $H s$ values approaching 0 (Fig. 4). The relationship between genetic diversity $(H)$ among populations from each region and geographic distance $(D)$ in kilometers from Chico, Butte County to Kings County was obtained as $H=0.0726 e^{-0.159 D}(r=0.9958 ; P<0.0001)$. This implies that the genetic diversity exponentially decreased as geographic distance increased.

Genetic diversity within populations of $B$. dothidea from other hosts also correlated with the postulated ages of these hosts in California (Fig. 5). For example, pycnidiospore isolates obtained from native California blackberry, willow, and walnut $(n=10$ each) were higher in genetic diversity $(H s=0.1689,0.1136$, and 0.08 , respectively) than isolates collected from relatively recently introduced plant species such as eucalyptus and pecan $(H s=$ 0.0148 and 0.0211 , respectively). In general, $B$. dothidea isolates collected from other hosts were more genetically diverse than isolates obtained from pistachio $(H s=0.0059)$ at the same site (Fig. 5).

Pathogenicity tests. All $60 \mathrm{~B}$. dothidea isolates obtained from other hosts (blackberry, eucalyptus, pecan, walnut, and willow), including 10 ascospore isolates taken from blackberry, produced the characteristic symptomology of Botryosphaeria panicle and shoot blight when inoculated onto pistachios (Table 1). Symptoms were indistinguishable from those obtained with the positive control isolates that originated from pistachio. Furthermore, all of these isolates produced characteristic pycnidia of $B$. dothidea on pistachio leaves after 2 weeks of incubation.

\section{DISCUSSION}

Our primary aim was to investigate the population structure of California isolates of $B$. dothidea collected from both commercial pistachio orchards and from a variety of other native and introduced plant species. We were interested in determining whether levels of genetic diversity correlated with the apparent absence of a sexual stage on pistachio and with the postulated age and direction of spread of the disease in the California Central Valley. We also wanted to determine whether $B$. dothidea isolates obtained from other hosts were capable of infecting pistachio and whether these isolates were similar to those recovered from pistachio, because vectoring of the pathogen from different plant species to pistachio via hemipteran vectors has been demonstrated $(12,15)$. This information may help resolve whether other plant species can serve as potential inoculum sources for pistachio.

Populations of $B$. dothidea obtained from California pistachio showed a remarkably low level of genetic diversity, with most of the $B$. dothidea isolates originating from pistachio forming a

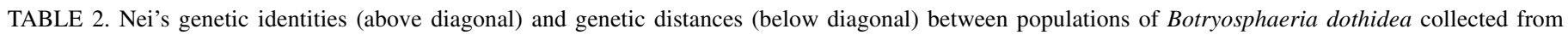
pistachio in six different locations

\begin{tabular}{|c|c|c|c|c|c|c|}
\hline Population & Chico & Montgomery & Hansen & San Joaquin & Madera & Kings \\
\hline Chico & $\cdots$ & 0.9958 & 0.9849 & 0.9799 & 0.9831 & 0.9831 \\
\hline Montgomery & 0.0042 & $\ldots$ & 0.9850 & 0.9802 & 0.9833 & 0.9833 \\
\hline Hansen & 0.0152 & 0.0151 & $\ldots$ & 0.9966 & 0.9997 & 0.9997 \\
\hline San Joaquin & 0.0203 & 0.0200 & 0.0034 & ... & 0.9969 & 0.9969 \\
\hline Madera & 0.0170 & 0.0169 & 0.0003 & 0.0031 & $\ldots$ & 1.0000 \\
\hline Kings & 0.0170 & 0.0169 & 0.0003 & 0.0031 & 0.0000 & $\ldots$ \\
\hline
\end{tabular}

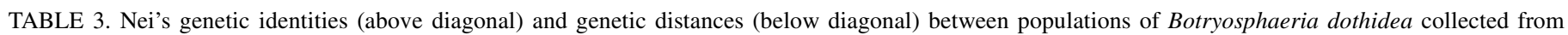
different hosts in Hansen, Glenn County

\begin{tabular}{|c|c|c|c|c|c|c|c|}
\hline Population & Blackberry & Eucalyptus & Pistachio & Pecan & Walnut & Willow & $\begin{array}{c}\text { Blackberry } \\
\text { (ascospore isolates) }\end{array}$ \\
\hline Blackberry & & 0.9798 & 0.9752 & 0.9730 & 0.9775 & 0.9873 & 0.7550 \\
\hline Eucalyptus & 0.0204 & $\ldots$ & 0.9911 & 0.9956 & 0.9905 & 0.9846 & 0.6839 \\
\hline Pistachio & 0.0251 & 0.0090 & $\ldots$ & 0.9829 & 0.9804 & 0.9761 & 0.6782 \\
\hline Pecan & 0.0274 & 0.0044 & 0.0173 & $\ldots$ & 0.9938 & 0.9834 & 0.6816 \\
\hline Walnut & 0.0227 & 0.0095 & 0.0198 & 0.0062 & $\ldots$ & 0.9780 & 0.7081 \\
\hline Willow & 0.0128 & 0.0155 & 0.0242 & 0.0167 & 0.0223 & $\ldots$ & 0.7270 \\
\hline Blackberry (ascospore isolates) & 0.2810 & 0.3800 & 0.3883 & 0.3883 & 0.3452 & 0.3188 & $\ldots$ \\
\hline
\end{tabular}


single group (group 1; Fig. 3). Furthermore, 13 of the 15 pistachio isolates collected from a single site, the Hansen Orchard (Table 1), in different years, showed identical PCR band profiles (Fig. 3). These data, combined with the fact that sexual reproductive structures (i.e., pseudothecia) have never been recovered from pistachio (12), indicate that this pathogen for the most part exists as asexual populations comprised of a few clonal lineages on California pistachio. This low level of genetic diversity also correlates well with the fact that Botryosphaeria panicle and shoot blight is a relatively recent disease on California pistachio $(9,20)$. Additionally, there was a low level of genetic diversity $(H s=0.0337)$ for 45 of the 50 pycnidiospore-derived isolates collected from other hosts in different years (Fig. 3). Conversely, 10 ascospore-derived isolates from single individual blackberry were relatively more diverse $(H s=0.0475)$, suggesting that the sexual stage of $B$. dothidea is not common on these other hosts. This agrees with a previous study (12) in which pycnidia of $B$. dothidea were recovered from more than 35 hosts, but pseudothecia (ascocarps) were found only occasionally on shoots of blackberry, olive, Pyracantha, and avocado. This suggests that $B$. dothidea is primarily asexual on California trees and vines.

In this study, 10 pycnidiospore isolates from blackberry showed higher genetic diversity than 10 ascospore-derived isolates from the same host (Fig. 5), although it was expected that ascosporederived isolates should be more diverse than pycnidiospore isolates (6). This discrepancy may be due to a sampling bias: all 10 ascospore isolates were collected from only three branches on a single blackberry plant, whereas the 10 pycnidiospore isolates originated from 10 different blackberry and were collected in different years (Table 1).

The genetic variation that we detected for pistachio isolates was primarily confined to two pistachio plantings in Butte County of special significance: the Montgomery Pistachio Orchard, the first orchard in which Botryosphaeria panicle and shoot blight disease was recorded (20), and the Chico USDA GR, representing pistachio trees originating from seed brought from Iran by W. E. Whitehouse over 70 years ago (27). These two sites are separated by only $10 \mathrm{~km}$. The 10 pistachio isolates obtained from the Chico site had significantly higher levels of genetic diversity $(F=51.04$; $P<0.0001)$ than all the isolates collected from commercial pistachio orchards throughout California. The Montgomery Orchard isolates also showed relatively high levels of diversity compared with isolates originating from central and southern California locations (Fig. 4). Most importantly, all of the haplotypes detected from Madera County and San Joaquin County, in the center of the state, and from Kings County, in the south, were identical to haplotypes recovered from most of the isolates taken from Chico and Montgomery, located in Butte County. This indicates that these two sites may have served as points of origin for the subse-

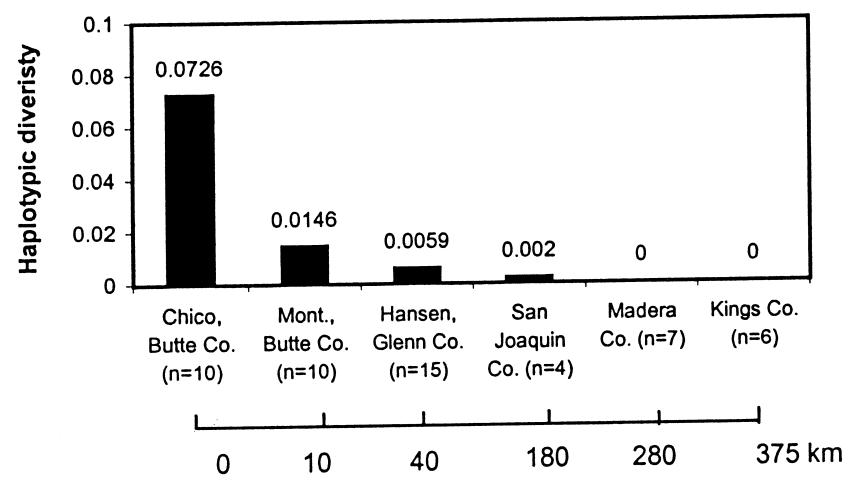

Fig. 4. Haplotypic diversity within populations of Botryosphaeria dothidea from different pistachio orchards in California, and distances in kilometers from origin of first pistachio planting. The overall genetic differentiation among six populations was $G s t=0.3467$. quent spread of pistachio Botryosphaeria panicle and shoot blight disease throughout California. The postulated direction of spread of the disease, from north to south, is further supported by the finding that declines in genetic diversity are correlated with increasing distance from the northern Chico, Butte County (Fig. 4).

Isolates of $B$. dothidea collected from nonpistachio hosts from the Hansen Orchard, Glenn County, showed much higher levels of genetic diversity than isolates collected from pistachio at the same site (Fig. 5). This is in agreement with reports of the pathogen on native plant species such as willow, walnut, and blackberry $(3,21)$, long before pistachio was introduced commercially into the state $(9,27)$. Although pistachio was introduced to California in 1929 (27), full commercialization of the crop only occurred in the early 1970s, and Botryosphaeria panicle and shoot blight was only detected in 1984 (20). Thus, B. dothidea on native plants should have been subjected more times to mutation for introduction of new variants to increase its genetic diversity.

In the present study, $56 \%$ of the pycnidiospore isolates of $B$. dothidea obtained from other hosts had identical haplotypes with $73 \%$ of the isolates obtained from pistachio. Although not enough genetic markers were used in this study to assign clear biological identity to these isolates, this finding does suggest that these isolates may be related genetically. This finding is further supported by pathogenicity tests, in which all 60 isolates from other hosts were capable of infecting pistachio and causing characteristic disease symptomology. This raises the strong possibility that native and introduced hosts for $B$. dothidea, other than pistachio, can and have historically served as potential inoculum sources when such plant species are found in close proximity to pistachio orchards. On the other hand, although all 60 isolates from other hosts caused disease symptoms on pistachios in greenhouse tests, there may exist a possibility that these isolates are different in virulence to pistachio in the field. Currently, there is mainly only one commercial pistachio cultivar (Kerman) growing in California. Thus, the genotypes of B. dothidea appearing on pistachio might be selected out of the overall pool of genotypes on other hosts by this pistachio cultivar.

$B$. dothidea has become a serious threat to the California pistachio industry in the last 2 decades $(9-11,14-16)$. Currently, there is no effective control for Botryosphaeria panicle and shoot blight, although there has been some recent success with multiple strobilurin fungicide sprays (14). The selection of resistant pistachio cultivars would provide the most durable form of control for this disease. Such a breeding program for resistance to Botryosphaeria panicle and shoot blight is predicated on a detailed knowledge of the genetic structure of $B$. dothidea populations. In this study we have demonstrated that although $B$. dothidea isolates obtained from California pistachio are primarily asexual and comprised of few clonal lineages, there does exist a degree of genetic diversity

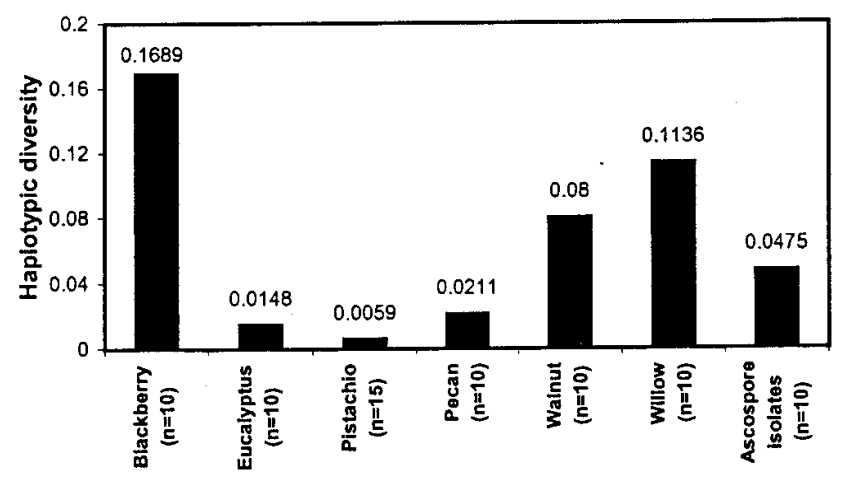

Fig. 5. Haplotypic diversity within populations of Botryosphaeria dothidea from other hosts and pistachio plantings in Hansen, Glenn County. The overall genetic differentiation among seven populations was $G s t=0.5485$. 
present primarily in isolates recovered from nonpistachio hosts and, most importantly, from isolates collected from the earliest pistachio plantings as well as the first orchard reporting the disease in California. Finally, in this study, we have demonstrated that $B$. dothidea isolates obtained from a number of nonpistachio hosts are fully capable of infecting pistachio and producing characteristic symptomology. These findings may have a direct impact on strategies for resistance breeding in this crop and the choice of isolates for screening of putative resistant cultivar lines (6). Toward this end, we have recently inoculated a set of 30 different pistachio cultivars using a collection of six $B$. dothidea isolates, one representative each of the six groups defined in this study, and have found several cultivars with varying degrees of resistance to some of these isolates (Z. Ma and T. J. Michailides, unpublished data).

\section{ACKNOWLEDGMENTS}

This research was supported in part from grants to T. J. Michailides from the California Pistachio Commission. We thank B. Pryor for critically reading this manuscript and D. P. Morgan and D. Felts for their excellent assistance.

\section{LITERATURE CITED}

1. California Pistachio Commission. 1999. California pistachio 1999 acreage and crop value. Pages 68-69 in: Calif. Pistachio Ind. Annu. Rep. 19992000.

2. Epstein, L., Arulsekar, S., Schmidt, D., and Daane, K. M. 2000. Determination of the nature and amount of genetic variation in Botryosphaeria and implications for control of this pathogen in pistachio. Page 126 in: Calif. Pistachio Ind. Annu. Rep. 1999-2000.

3. Faucett, H. S. 1915. "Melaxuma" of the walnut, Juglans regia. (A preliminary report) Calif. Agric. Exp. Stn. Bull. 262:133-148.

4. Levis, C., Giraud, T., Dutertre, M., Fortini, D., and Brygoo, Y. 1997. Telomeric DNA of Botrytis cinerea: A useful tool for strain identification. FEMS Microbiol. Lett. 157:267-272.

5. Luttrell, E. S. 1950. Botryosphaeria stem canker of elm. Plant Dis. Rep. 34:138-139.

6. McDonald, B. A. 1997. The population genetic of fungi: Tools and techniques. Phytopathology 87:448-453.

7. McDonald, B. A., and Martinez, J. P. 1990. Restriction fragment length polymorphisms in Septoria tritici occur at high frequency. Curr. Genet. 17:133-138.

8. Meyer, W., Mitchell, T. G., Freedman, E. Z., and Vilgalys, R. 1993. Hybridization probes for conventional DNA fingerprinting used as single primers in the polymerase chain reaction to distinguish strains of Cryptococcus neoformans. J. Clin. Microbiol. 31:2274-2280.

9. Michailides, T. J. 1991. Pathogenicity, distribution, sources of inoculum, and infection courts of Botryosphaeria dothidea on pistachio. Phytopathology 81:566-573.

10. Michailides, T. J., and Morgan, D. P. 1992. Effects of temperature and wetness duration on infection of pistachio by Botryosphaeria dothidea and management of disease by reducing duration of irrigation. Phytopathology 82:1399-1406.
11. Michailides, T. J., and Morgan, D. P. 1993. Spore release by Botryosphaeria dothidea in pistachio orchards and disease control by altering the trajectory angle of sprinklers. Phytopathology 83:145-152.

12. Michailides, T. J., Morgan, D. P., and Felts, D. 2000. Other hosts of Botryosphaeria dothidea and their relation to pistachio Botryosphaeria blight. Pages 135-136 in: Calif. Pistachio Ind. Annu. Rep. 1999-2000.

13. Michailides, T. J., Morgan, D. P., and Felts, D. 2001. Collection and characterization of Botryosphaeria dothidea from various hosts and pathogenicity studies on pistachio. KAC Plant Prot. Q. 11:3-8.

14. Michailides, T. J., Morgan, D. P., Felts, D., Krueger, W., and Weinberger, G. 2000. Chemical control of Botryosphaeria blight of pistachio in California. Pages 123-124 in: Calif. Pistachio Ind. Annu. Rep. 1999-2000.

15. Michailides, T. J., Morgan, D. P., Felts, D., and Ribiero, B. 1997. Disease monitoring, prediction and spread of Botryosphaeria dothidea in central California pistachio orchards. Pages 73-81 in: Calif. Pistachio Ind. Annu. Rep. 1996-1997.

16. Michailides, T. J., Morgan, D. P., and Sullivan, A. 1996. Spread of Botryosphaeria dothidea in pistachio orchards of the San Joaquin Valley. Pages 123-128 in: Calif. Pistachio Ind. Annu. Rep. 1995-1996.

17. Michailides, T. J., Teriotdale, B. L., and Weinberger, G. 1999. Botryosphaeria panicle and shoot blight management program for California pistachios. Calif. Pistachio Ind. Botryosphaeria Man. P53.

18. Nei, M. 1987. Molecular Evolutionary Genetics. Columbia University Press, New York.

19. Nei, M., and Li, W. H. 1979. Mathematical model for studying genetic variation in terms of restriction endonucleases. Proc. Natl. Acad. Sci. USA 76:5269-5273.

20. Rice, R. E., Uyemoto, J. K., Ogawa, J. M., and Pemberton, W. M. 1985. New findings on pistachio problems. Calif. Agric. 39:15-18.

21. Smith, C. O. 1934. Inoculations showing the wide host range of Botryosphaeria ribis. J. Agric. Res. 49:467-470.

22. Smith, D. R., Michailides, T. J., and Stanosz, G. R. 2000. Fusicoccum pathogen on California pistachio trees is not the anamorph of Botryosphaeria dothidea. (Abstr.) Phytopathology 90(suppl.):S73.

23. Smith, D. R., and Stanosz, G. R. 1999. RAPD marker differentiation of Botryosphaeria dothidea from other fungi with Fusicoccum anamophs (Abstr.). Phytopathology 89(suppl.):S74.

24. Sunnucks, P. 2000. Efficient genetic markers for population biology. Trends Ecol. Evol. 15:199-203.

25. Sutton, T. B., and Boyne, J. V. 1983. Inoculum availability and pathogenic variation in Botryosphaeria dothidea in apple production areas of North Carolina. Plant Dis. 67:503-506.

26. Taylor, J. W., Geiser, D. M., Burt, A., and Koufopanou, V. 1999. The evolutionary biology and population genetics underlying fungal strain typing. Clin. Microbiol. Rev. 12:126-146.

27. Vietmeyer, N. 1984. American pistachio. Horticulture (Sept.):32-38.

28. Weaver, D. J. 1974. A gummosis disease of peach trees caused by Botryosphaeria dothidea. Phytopathology 64:1429-1432.

29. Weising, K., Atkinson, R. G., and Gardner, R. C. 1995. Genomic fingerprinting by microsatellite-primed PCR: A critical evaluation. PCR Methods Appl. 4:249-255.

30. Witcher, W., and Clayton, C. N. 1963. Blueberry stem blight caused by Botryosphaeria dothidea (B. ribis). Phytopathology 53:705-712.

31. Wolf, F. T., and Wolf, F. A. 1939. A study of Botryosphaeria ribis on willow. Mycologia 31:217-227.

32. Worrall, J. J., Correll, J. C., and McCain, A. H. 1986. Pathogenicity and teleomorph-anamorph connection of Botryosphaeria dothidea on $\mathrm{Se}$ quoiadendron giganteum and Sequoia sempervirens. Plant Dis. 70: 757-759. 